\title{
Treatment of Fish Effluents in Moving Bed Bioreactor Process using Natural Carriers as Biomass Support
}

\author{
A. Fathi ${ }^{1}$, N. Boutaleb ${ }^{1 *}$, B. Bahlaouan ${ }^{1,2}$, D. Lakhal ${ }^{1}$, M. Bennani ${ }^{3}$, S. Lazar $^{1}$, S. El Antri ${ }^{1}$ \\ ${ }^{1}$ Hassan II University of Casablanca. Laboratory of Biochemistry, Environment, and Agri-Food, URAC36, 20650 Morocco. \\ ${ }^{2}$ Higher Institutes of the Nursing Professions and Techniques of Health (ISPITS), Casablanca 22500, Morocco \\ ${ }^{3}$ Institut Pasteur Casablanca Morocco, Laboratory of Physico-Chemical Analysis of Water, Food and Environment
}

\begin{abstract}
A treatment of effluents of the fishing industry by biological processes has been studied. The results of the experiments have shown that the use of sardine's scales, drums scales, and snails shells as a support of biomass is promising and offer an alternative of industrial supports.

The efficiency of organic matter abatement achieved by this study, using sardine's scales as a moving bed for biofilm development is better, compared to that obtained using kaldness supports. For the efficiency of suspended matter reduction, higher performance is recorded with drum scales, snail shells with respective yield of $83.01 \%$ and $71.92 \%$.

For phosphorus and nitrogen treatment, the best yield of treatment is obtained by using drums scales, snails shells and the industrial carriers.
\end{abstract}

Keywords:Biological treatment, Fish effluents, Biofilm, Organic pollution, Bio-carriers, Biomass.

\section{INTRODUCTION}

Morocco is considered the world's leading producer and exporter of sardines and one of the largest exporters of seaweed and fishmeal. 85\% of the seafood is exported [1]. The fishery processing industry occupies an important place in the Moroccan economy, providing $50 \%$ of agri-food exports and $12 \%$ of total Moroccan exports. This industry processes about $70 \%$ of the coastal fisheries catch and exports about $85 \%$ of its production to about 100 countries around the world [2].

Morocco currently constitutes a fundamental regional stage for the valorization and export of fishery products [2].

All operations used in fish processing plants generate high salinity wastewater containing a high concentration of various contaminants such as organic matter and fats [3].

It is predicted that about $90 \%$ of available water resources will be consumed in the next 15 years [4]. The recovery of water and its reuse are therefore necessary for the years to come. New, more advanced effluent treatment technologies, able to provide high quality treated water, have replaced the treatment techniques used in earlier times.

For example, the use of biofilm systems is pleasing in smaller applications because of their simplified procedures, lower maintenance costs, and increased reliability.

Today, several hundred industries around the world use MBBR for wastewater treatment in domestic and industrial applications [5]. MBBRs are continuously operating biofilm reactor and similar to the activated sludge process, with the addition of small carrier elements which move along with the water in the reactor [5].

The colonization supports carry the microorganism throughout the reactor [6]. As the biofilm grows on the protected interior surface of the media, the surface of the biofilm has become an important design parameter.

The first bio-carriers used in MBBR systems were the $\mathrm{K}$ series AnoxKaldnes ${ }^{\mathrm{TM}}$. These bio carriers are made of polyethylene with a density of $0.95 \mathrm{~g} \mathrm{~cm}-3$. The $\mathrm{K}$ bio carrier series is characterized by its unique dimensions, the surface available for biofilm growth, and the different sections defined by the rims. The effective area available is the protected section of the entire bio carrier that is free from contact with other bio carriers during the agitation operation [7].

than that of water. These media now exist under many brands, but AnoxKaldnes K3 carriers and especially K5 carriers are often preferred in new industries.

The performance of the MBBR process depends on the size of the biofilm and therefore the specific surface area of the carrier [8].

This performance also depends on the presence of dissolved oxygen. For maximum removal of COD, Wang et al. (2006) [9] advised to keep dissolved oxygen (DO) in the reactor above $2 \mathrm{mg} / \mathrm{L}$. They also found that by decreasing OD from 2 to $1 \mathrm{mg} / \mathrm{L}$, the removal efficiency of COD decreased by $13 \%$, indicating that OD is also a limiting factor in the performance of the bioreactor [8].

Sufficient agitation is ideal for optimizing system performance. The nature of the support used is important for the development of a very thin, uniformly distributed and smooth biofilm, which will subsequently allow the transport of the substrate and oxygen on the surface of the biofilm [8]

Agitation in MBBR systems is difficult, due to the stagnant potential of the carrier and especially in the early phases of biofilm formation. In fact, when the supports are not colonized and the biofilm is not yet fixed, they can be found floating because of their lower density than that of water. As the microorganisms begin to adhere and expand on the protected surface of the bio carrier, they become denser (e.g., higher density than water) and as a consequence, the agitation capacity is enhanced [7]. 
The most common fillings used are those made of polyethylene or high-density polyethylene materials, such as those mentioned previously, but the use of natural fillings remains more profitable, either in regard to their bioavailability or in terms of their low cost.

Several types of natural fillings have been used to date, snail shells, sardine's scales and oyster shells have been studied and have shown excellent results in terms of biofilm formation and organic matter degradation of a dairy [10-12].

Another study has also shown that cocoa flakes can also be used as a biofiltration carrier for the treatment of agro-food effluents with high organic matter content [13].

Talbot et al. (2004) have in the same way submitted a certificate for a biofilter based on coconut shells, and this same biofilter is used for wastewater treatment [14].

The aim of this present work is to valorize the power of sardine scales, snail shells and drum scales as a fungal biomass carrier for the biological treatment of effluents from fishing industries.

\section{MATERIALS AND METHODS}

\section{A. Preparation of biomass}

Reference strains of Aspergillus niger (11G323A) were used in this study. Several species of the genus Aspergillus are known for their resistance to pesticides [15], antifungals [16], lead [17], and stressful conditions (e.g. presence of acid or base, detergents, phenolic products...) and for their efficiency in the degradation of the pollution [18-20]. The fungal cells were propagated before each use on PDA agar (Potatoes Dextrose Agar), followed by incubation for $72 \mathrm{~h}$ at $30^{\circ} \mathrm{C}$.

The culture media used is the PDA medium for the cultivation of mushrooms in a solid medium. For cultures in liquid media, Malt broth is used (3\% Malt extract, 2\% Peptone, and $1 \%$ autolytic yeast extract).

The culture media were sterilized by autoclaving at $120^{\circ} \mathrm{C}$ for 20 minutes. The fungus cells were then separated by centrifugation $(4800 \mathrm{~g}, 20 \mathrm{~min})$ and finally added to the bioreactor containing synthetic effluent.

\section{B. Preparation and characterization of the effluent}

As in most processing industries, fish processing operations produce wastewater that contains organic contaminants in soluble, colloidal and particulate form [21]. We chose to use a synthetic effluent whose composition was similar to the industrial one. The synthetic effluent was prepared using $160 \mathrm{~g}$ heads, viscera, bones, and tails of fresh sardines (Sardinella sp.) and $400 \mathrm{ml}$ of distilled water. The mixture was homogenized in a blender then sieved to obtain a concentrate. The concentrate was diluted in distilled water to obtain the desired concentration [22]

\section{Biomass support}

Sardine's scales

The scales of Sardina pilchardus are large, silvery, fragile and do not extend to the head, they are translucent lamellae and present a certain diversity of form.

These scales were collected, washed several times with demineralized hot water, dried for $24 \mathrm{~h}$ at $60^{\circ} \mathrm{C}$ and stored at room temperature [10].

\section{Snails shells}

The shells of the family Helicidae were used for this study. In order to prepare our sample, the shells obtained from snails were then cleaned with hot water. The shells were washed again with distilled water, dried in the sun and perforated to a diameter of one millimeter in order to promote the diffusion of the effluent inside.

\section{Drums scales}

A species of fish scales was tested in this study as support forming biofilm, Umbrina roncador (drums scales). The fish scales were collected and washed with hot demineralized water, then dried overnight at $60{ }^{\circ} \mathrm{C}$ and stocked at ambient temperature.

A preliminary study, in which various amounts of materials ranging from $1 \mathrm{~g} / \mathrm{L}$ to $5 \mathrm{~g} / \mathrm{L}$ were tested, showed a better yield from $2 \mathrm{~g} / \mathrm{L}$ for sardines scales and $4 \mathrm{~g} / \mathrm{L}$ for drums scales.

The amount of scales used has been then optimized according to the study conducted by Ait cheikh et al. (2014) et El Jaafari et al. (2014) [10, 19].

\section{Industrial reference refill}

Kaldnes K3 supports were used as biomass support in MBBR (Moving Bed Biofilm Reactor) reactors. This type of support has a specific surface area of $500 \mathrm{~m} 2 / \mathrm{m} 3$ [7].

\section{Bioreactor}

The bioreactor used consists of a simple glass tank with a total volume of 20 liters, the supply of oxygen is provided by fine aerators bubble from the base of the reactor. The homogenization and agitation of the effluent are provided by a mechanical stirrer.

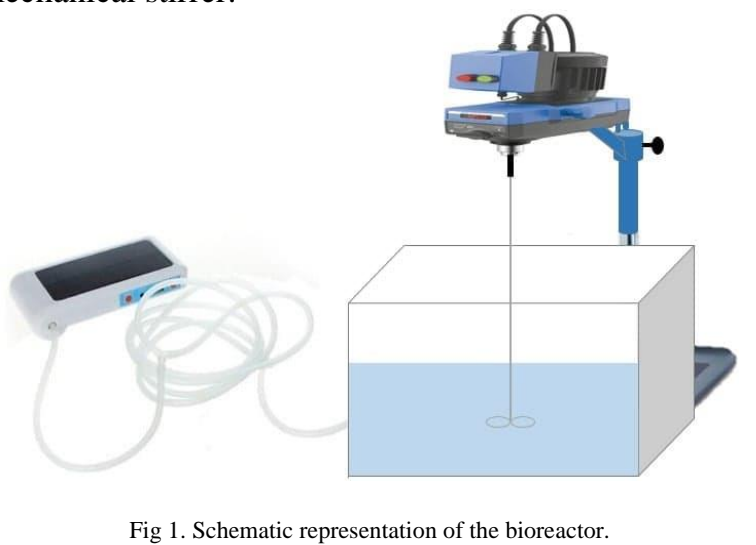

\section{E. Measurement of purification performance}

Several tests were conducted from the start of the tests up to 24 hours (Table 1): The total nitrogen was determined by the thermal catalytic oxidation with a high-temperature TOC 
analyzer (Model: TOC-L Shimadzu, Japan). The chemical oxygen demand (COD) was determined according to the French standard NFT90-101: 2001 [23]. The phosphorus was controlled by a colorimetric method using the phosphomolybdic complex in accordance with the German standard DIN EN ISO 6878-2004-09 (2004) [24]. The suspended matter (MES) was determined by the filtration of a volume of the effluent on a filter paper $(0.45 \mu \mathrm{m})$ according to the method described by Rodier et al., (1996) [25].

\section{TABLE 1. CONTROLLING THE PERFORMANCE OF THE DEPOLLUTION.}

\begin{tabular}{cc}
\hline Parameter & The method used \\
\hline Total nitrogen & Total organic carbon analyzer (TOC-L Shimadzu, \\
Japan) & $\begin{array}{c}\text { French standard NFT90-101: 2001 } \\
\text { CoD }\end{array}$ \\
$\begin{array}{c}\text { Suspended } \\
\text { Matter }\end{array}$ & According to the method described by Rodier et \\
al., (1996).
\end{tabular}

A microscopic observation in SEM was also conducted to study the colonization of microorganisms on supports.

\section{RESULTS AND DISCUSSION}

\section{A. Purification performance}

Table 2 summarizes the efficiency of the various wastewater pollution parameters with the different natural supports tested.

TABLE 2. THE EFFICIENCY OF THE VARIOUS WASTEWATER POLLUTION PARAMETERS WITH THE DIFFERENT NATURAL SUPPORTS TESTED.

\begin{tabular}{|l|c|c|c|c|c|}
\hline & $\begin{array}{c}\text { Temps } \\
(\mathrm{h})\end{array}$ & \% COD & \% phosphorus & $\begin{array}{c}\text { \% total } \\
\text { nitrogen }\end{array}$ & $\begin{array}{c}\text { \% suspended } \\
\text { matter }\end{array}$ \\
\hline \multirow{4}{*}{ Kaldnes } & 6 & 90.00 & 64.71 & 21.07 & 16.21 \\
\cline { 2 - 6 } & 12 & 93.96 & 77.57 & 23.79 & 2.70 \\
\cline { 2 - 6 } & 24 & 100.00 & 85.88 & 32.25 & 35.13 \\
\hline \multirow{2}{*}{$\begin{array}{l}\text { Sardine's } \\
\text { scales }\end{array}$} & 6 & 90.00 & 58.41 & 3.38 & 22.22 \\
\cline { 2 - 6 } & 12 & 100.00 & 63.86 & 7.77 & 51.85 \\
\hline \multirow{2}{*}{$\begin{array}{l}\text { Drums } \\
\text { scales }\end{array}$} & 24 & 100.00 & 64.56 & 13.19 & 48.14 \\
\cline { 2 - 6 } & 6 & 44.12 & 56.18 & 7.69 & 73.58 \\
\hline \multirow{2}{*}{$\begin{array}{l}\text { Snails } \\
\text { shells }\end{array}$} & 24 & 41.18 & 64.54 & 30.77 & 86.79 \\
\cline { 2 - 6 } & 6 & 29.41 & 63.50 & 6.66 & 70.17 \\
\cline { 2 - 6 } & 24 & 47.06 & 58.65 & 15.57 & 78.94 \\
\hline \multirow{2}{*}{} & 24.12 & 73.42 & 28.89 & 71.92 \\
\hline
\end{tabular}

$C O D$

The degradation of organic matter increases with time and varies according to the nature of the carrier used, the maximal abatement is recorded for sardine scales with a percentage of $100 \%$ at the end of the processing, and this same percentage has been registered for Kaldnes carriers. A $92.13 \%$ abatement rate was recorded for the treatment of synthetic domestic effluent [26], in another context, the average soluble COD removal efficiency for an MBBR system as a whole, used for municipal wastewater treatment was $95.7 \%$ [27].

The decrease in chemical oxygen demand through time is due to the utilization of organic compounds by Aspergillus niger for its growth [11]. High organic matter (COD) wastewater is a major problem, contributing to eutrophication, oxygen consumption, and toxicity when it is released into the natural environment [27].

COD is frequently measured as a time-saving marker of the organic pollutant in water. The efficacy of the purification process is given as a proportion of the organic matter that has been purified during the treatment cycle [28].

\section{Suspended Matter}

All essays show an increase in the percentage of abatement of the MS, we note that this percentage decreases after 12 hours of treatment.

In biological treatment, the percentage of suspended solids is expected to increase over time. The decrease in this percentage is explained by the fact that the fungi used during the experiment adhere to the bioreactor wall and form a biofilm which, after being detached, causes an increase in the suspended material [20].

The increase in suspended solids in biological treatment can be explained by the detachment of biomass from the carrier, or in the use of natural carriers, this increase can be associated with the deterioration and loss of the carrier itself [13].

\section{Phosphorus}

Phosphorus is one of the leading macronutrients that are critical for both growth and biological evolution [29].

The predominant phosphorous components in the sewage water are mostly in the orthophosphate form coupled to a small organic phosphorus fraction [5].

The microbial solubilisation process of phosphate is the result of organic acid generation such as citric acid, which is combined with medium acidification [30]. Aspergillus species are part of fungal strains known to have phosphate solubilisation properties.

Filamentous fungi are largely employed as organic acid producers and Aspergillus niger was tested in a fermentation system or directly inoculated into the soil in order to solubilize rock phosphate [31].

Microorganisms use the phosphorus for their cellular maintenance, nucleic acid production, cell membrane development and the chemical energy transfer reactions, and they retain it also as a reserve [32].

An interesting percentage of phosphorus removal is recorded towards the end of the treatment, according to table 4 ; the percentages of abatement are $85.88 \%$ for Kaldnes supports, $74.30 \%$ for drums scales, $73.42 \%$ for sardine's scales and $64.56 \%$ for snails shells. We notice that the natural's supports tested, have the same performance in removal than the Kaldnes.

Kermani et al. (2009) and Ait Cheikh et al. (2014) have studied the evolution of phosphorus degradation from synthetic effluent using an MBBR reactor. The respective abatement rates are $95.8 \%$ and $81.76 \%[10,33]$.

\section{Total nitrogen}

Total nitrogen elimination in sewage treatment plants is most frequently achieved in a two-step process, such as nitrification and denitrification. Nitrification converts ammonia into a highly oxidized nitrogen compound in the 
form of nitrite or nitrate, which is then transformed into nitrogen gas in the further denitrification process [27]. This decrease of nitrogen is the result of the incorporation of nitrogen into the new Aspergillus Niger produced cells [34].

\section{B. Statistical analysis - Principal Component Analysis (PCA)}

To be able to compare the degrees of similarities (or differences) between the biofilm colonization carriers in the abatement of pollution with its various forms, the generated PCA map is presented in Figure 2.
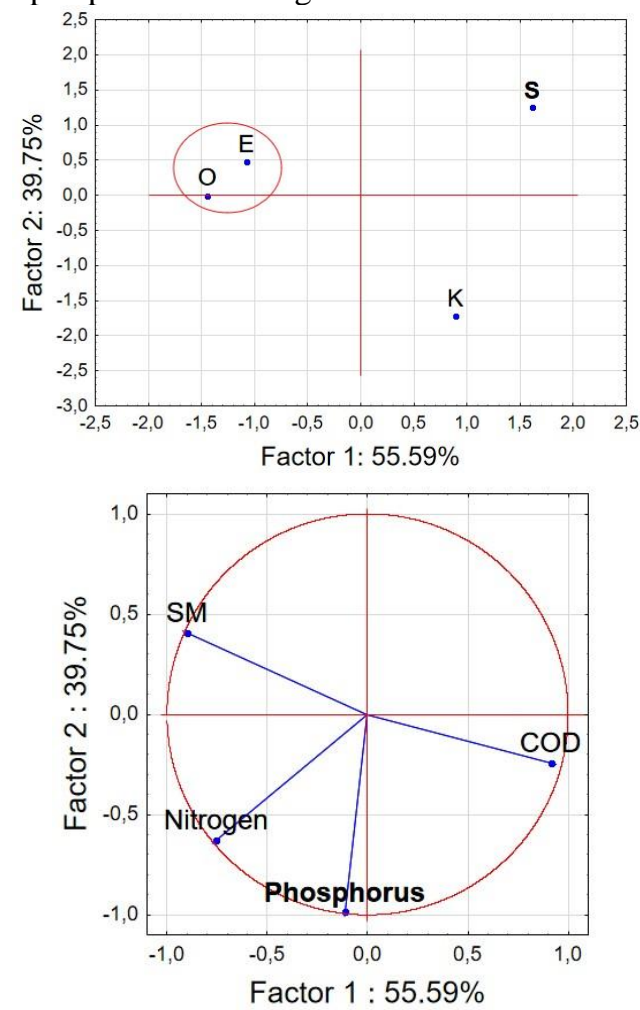

Fig 2. The biplot consisting projection on PC1 (55.59\%) and PC2 $(39.75 \%)$, of different cases of biological treatment using different carriers; correlation circle between principal components and pollution parameters.

According to Figure 2, it can be noticed that for biological treatment of fish effluents in MBBR bioreactors:

Drums scales and snails shells have almost the same performance in the treatment of pollution, so they constitute a single category.

For COD, sardine scales show better performances similar to those of Kaldnes synthetic supports. On the other hand, they were the most inefficient of all the supports for the treatment of phosphorus pollution.

For the treatment of suspended matter MES, drums scales and snails shells are more efficient compared to sardines scales and Kaldnes supports.

Figure 3 shows the images of scanning electron microscopy (SEM) of the different surfaces colonized by A. niger at the end of the treatment.

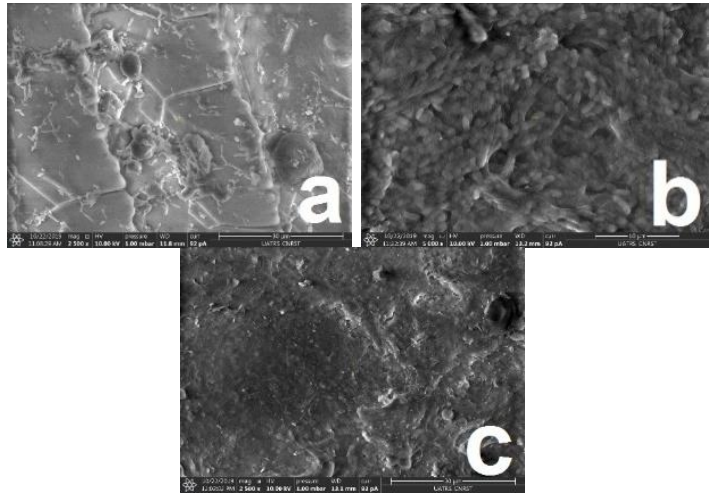

Fig. 3. SEM surface colonized by A. niger (10K magnification). (a) using drums scales, (b) using sardine's scales and (c) by using snail's shells.

These images show that colonization on sardine's scales is greater than that observed on other media. These results are in good agreement with the results of figure 2, for which we have noted two categories of treatment concerning the natural supports:

The first constituted by scales of sardines (well correlated with the reduction of the COD) and the second constituted by the two other supports. Several bacterial cells and an exocellular matrix are clearly visible on the SEM images.

\section{CONCLUSION}

The monitoring of conventional parameters shows that the introduction of natural supports improves the properties and quality of clearance, offering the potential for colonization of microorganisms and biofilm formation on the surface. Biological treatment in a moving bed with a purely biological bio-carriers has proved to be very effective economic and ecological. The fungal growth showed very promising results reflected in the high degradation rate of organic matter registered during the study.

\section{ACKNOWLEDGMENTS}

CNRST for its financial support of PPR2/2016/21.

Research Center of Materials and Energy of the Hassan II University of Casablanca.

\section{REFERENCES}

[1] Chambre Française de commerce et d'industrie au Maroc (2018). URL : $\quad$ https://www.cfcim.org/wpcontent/uploads/2018/09/Maroc_Le-marche-de-la-filiere-mer.pdf. Accessed Nov 6, 2019 (2018).

[2] National federation of seafood processing and valorization industries, FENIP. URL: http://www.fenip.com/fenip/contenu.asp?id_rub=13\&ID_SRUB=2 3 . Accessed Nov 6, 2019 (2019).

[3] Jemli, M., Karray, F., Feki, F., Loukil, S., Mhiri, N., Aloui, F., Sayadi, S. : Biological treatment of fish processing wastewater: A case study from Sfax City (Southeastern Tunisia). Int. J. Environ. Sci. 30, 102-112 (2015).

[4] Fazal, S., Zhang, B., Zhong, Z., Gao, L., Lu, X. : Membrane Separation Technology on Pharmaceutical Wastewater by Using MBR (Membrane Bioreactor). J. Environ. Prot. Sci. 6, 299-307 (2015).

[5] Shahot, K., Idris, A., Omar, R., Yusoff, H.M. : Review on Biofilm Processes for Wastewater Treatment. Life Sci. J. 11, 1-13 (2014). 
[6] Leiknes, T., Odegaard, H. : The development of a biofilm membrane bioreactor. Desalination. 202, 135-143 (2007).

[7] Di Biase, A., Kowalski, M.S., Devlin, T.R., Oleszkiewicz, J.A. : Moving bed biofilm reactor technology in municipal wastewater treatment: A review. J. Environ. Manage. 247, 849-866 (2019).

[8] Barwal, A., Chaudhary, R. : To study the performance of bio carriers in moving bed biofilm reactor (MBBR) technology and kinetics of biofilm for retrofitting the existing aerobic treatment systems: a review. Rev Environ Sci Biotechnol. 13, 285-299 (2014).

[9] Wang, X.J., Xia, S.Q., Chen, L., Zhao, J.F., Renault, N.J., Chovelon, J.M. : Nutrients removal from municipal wastewater by chemical precipitation in a moving bed biofilm reactor. Process Biochem. 41, 824-828 (2006)

[10] Aitcheikh, A., Boutaleb, N., Bahlaouan, B., El Jaafari, A., Taiek, T., Bennani, M., Lazar, S., El Antri, S. Dairy : Wastewater Treatment in Moving Bed Biofilm Reactor using Sardine's Scales as Biomass Support. Int. J. Eng. Res. Technol. 3, 1036 (2014).

[11] Aitcheikh, A., Boutaleb, N., Bahlaouan, B., El Omari, H., El Jaafari, A., Lazar, S., El Antri, S. : Snail shells: a new ecological packing for moving bed reactor MBBR in the biological treatment of dairy effluent. Global journal of bio-science and biotechnology (GJBB). 5, 492-497 (2016)

[12] Aitcheikh, A., Boutaleb, N., Bahlaouan, B., Bennani, M., Lazar, S., El Antri, S. : Treatment of Dairy Effluents in Biological FluidizedBed Reactors using Oyster Shells as Ecological Garnishing. Res. J. Appl. Sci. Eng. Tech. 15, 362-3690 (2018a)

[13] Turcotte, V., Blais, J.F., Mercier, G., Drogui, P. : Utilisation des écailles de cacao comme support de biofiltration pour le traitement d'effluents de l'industrie agro-alimentaire. J.Environ. Eng. Sci. 8, 277-288 (2013)

[14] Talbot, P., Pettigrew, D., Lacasse, R., Bélanger, G., Arcand, Y., Dautais, J.P. : Coconut mesocarp-based biofilter material and its use in a wastewater treatment system. American patent, no 2004/0124139 A1 (2004)

[15] Marinho, G., Barbosa, B.C.A., Rodrigues, K., Aquino, M., Pereira, L. : Potential of the filamentous fungus Aspergillus niger AN 400 to degrade Atrazine in wastewaters. Biocatalysis and Agricultural Biotechnology. 9, 162-167 (2017)

[16] Van Der Linden JW1, Warris A, Verweij PE. : Aspergillus species intrinsically resistant to antifungal agents. J. Mycol. Med. 49, 82-89 (2011).

[17] Dursun, A.Y., Uslu, G., Cuci, Y., Aksu, Z. : Bioaccumulation of copper (II), lead (II) and chromium (VI) by growing Aspergillus niger. Process. Biochem. 38, 1647-1651 (2003).

[18] Lacina, C., Germain, G., Agathos, N.S. : Utilization of fungi for biotreatment of raw wastewaters. Afr. J. Biotechnol. 2, 620-630 (2003).

[19] El Jaafari, A., Boutaleb, N., Bahlaouan, B., Taiek, T., Bennani, M., Lazar, S., El Antri, S. : Use of Three Types of Fish Scales as Biomass Support in Moving Bed Biofilm Reactor for Biological Treatment of Dairy Wastewater. Int. J. Eng. Res. Technol. 3 (2014).
[20] Aitcheikh, A., Boutaleb, N., Bahlaouan, B., Bennani, M., Lazar, S., El Antri, S. : Utilisation d'un lit fixe d'origine naturelle pour le traitement biologique d'effluents laitiers. Déchets sciences et techniques. 78 (2018b).

[21] Chowdhury, P., Viraraghavan, T., Srinivasan, A. : Biologica treatment processes for fish processing wastewater - A review. Bioresour. Technol. 101, 439-449 (2010).

[22] Duarte, J.G., Silva, L.L.S., Freire, D.M.G., Cammarota, M.C., Gutarra, M.L.E. : Enzymatic hydrolysis and anaerobic biologica treatment of fish industry effluent: Evaluation of the mesophilic and thermophilic conditions. Renew. Energy. 83, 455-462 (2015).

[23] NFT90-101: Qualité de l'eau - Détermination de la demande chimique en oxygène (DCO) (2001)

[24] DIN EN ISO 6878-2004-09: Qualité de l'eau - Dosage du phosphore - Méthode photométrique au molybdate d'ammonium (2004).

[25] Rodier J., Bazin C., Broutin J.P., Champsaur H. : L'analyse de l'eau - Eaux naturelles, eaux résiduaires, eau de mer. Technique et ingénierie, Dunod. 8e édition, p : 1600 (1996).

[26] Adabju, A. : Specific Moving Bed Biofilm Reactor for Organic Removal from Synthetic Municipal Wastewater. A thesis submitted to fulfilment of the requirements for the degree of Master of Engineering. University of Technology, Sydney Faculty of Engineering (2013)

[27] Kermani, M., Bina, B., Movahedian, H., Amin, M.M., Nikaein, M. Application of Moving Bed Biofilm Process for Biological Organics and Nutrients Removal from Municipal Wastewater. Am. J. Environ. Sci.4, 682-689 (2008)

[28] Kawan, J.A., Rakmi, A.R., Bin Jaafar, O., Suja, F. : Polishing of Chemical Oxygen Demand (COD) Using Moving Bed Bio- Reactor. Appl.Mech.Mater. 773-774, 1281-1285 (2015).

[29] Ahmed, N., Shahab, S. : Phosphate Solubilization: Their Mechanism Genetics and Application. The Internet Journal of Microbiology. 9 (2009).

[30] Vassilev, N., Eichler-Lobermann, B., Reyes Requena, A., Martos, V., Lopez, A., Vassileva, M. : Biodiesel by-products and Psolubilizing microorganisms. Rev. Environ. Sci Bio. 15, 627-638 (2016).

[31] Yadav, J., Verma, J.P., Tiwari, K.N. : Solubilization of Tricalcium Phosphate by Fungus Aspergillus niger at Different Carbon Source and Salinity. Trends. Appl. Sci. Res. 6, 606-613 (2011).

[32] Krishnaswamy, U., Muthuchamy, M., Perumalsamy, L. : Biologica removal of phosphate from synthetic wastewater using bacterial consortium. Iran. J. Biotechnol. 9, 37-49 (2011).

[33] Kermani, M., Bina, B., Movahedian, H., Amin, M.M., Nikaein, M. Biological phosphorus and nitrogen removal from wastewater using moving bed biofilm process. Iran. J. Biotechnol. 7 (2009).

[34] De Oliveira Mendes, G., Galvez, A., Vassileva, M., Vassilev, N. : Fermentation liquid containing microbially solubilized $P$ significantly improved plant growth and $\mathrm{P}$ uptake in both soil and soilless experiments. Appl. Soil. Ecol. 117-118, 208-211 (2017). 